\title{
A Quantum Chemistry Approach to the Force Fields of the Thionyl and Selenyl Halides, $\mathrm{SOX}_{2}$ and $\mathrm{SeOX}_{2}$
}

Lis E. Fernández ${ }^{\mathrm{a}}$ and Eduardo L. Varetti ${ }^{\mathrm{b}, \mathrm{c}}$

${ }^{a}$ Instituto de Química y Física, Facultad de Bioquímica, Química y Farmacia, Universidad, Nacional de Tucumán, San Lorenzo 456, 4000 S.M. de Tucumán, R. Argentina

b Centro de Química Inorgánica (CEQUINOR, CONICET-UNLP), Departamento de Química, Facultad de Ciencias Exactas, Universidad Nacional de La Plata, C.Correo 962, 1900 La Plata, R. Argentina

${ }^{c}$ Member of the Carrera del Investigador Científico, CONICET, R. Argentina

Reprint requests to E. L. Varetti. E-mail: varetti@quimica.unlp.edu.ar

Z. Naturforsch. 2007, 62b, 1491 - 1496; received July 16, 2007

Force fields and vibrational frequencies were calculated for the molecules $\mathrm{SOX}_{2}$ and $\mathrm{SeOX}_{2}$, with $\mathrm{X}=\mathrm{F}, \mathrm{Cl}, \mathrm{Br}$, using DFT techniques. The previously available experimental data and assignments for the six molecules were confirmed by the theoretical results. These data were subsequently used in the definition of the corresponding scaled quantum mechanics (SQM) force fields. A comparison of the obtained internal force constants is made with results reported by other authors for the studied species.

Key words: Thionyl Halides, Selenyl Halides, Force Constants, Structure, DFT Calculations

\section{Introduction}

The force fields of the sulfuryl halides of formula $\mathrm{SO}_{2} \mathrm{X}_{2}$ and $\mathrm{SO}_{2} \mathrm{XF}$ were studied a few years ago in this laboratory $[1,2]$. The thionyl and selenyl halides are now considered with the purpose of a revision of the published vibrational data and to calculate the corresponding sets of force constants, appropriately scaled to reproduce the experimental frequencies.

This kind of calculation should be based preferably on frequency data obtained for the substances in the gas phase, in order to minimize molecular interactions. This is particularly important for the $\mathrm{SeOX}_{2}$ species, where the tendency of $\mathrm{Se}(\mathrm{IV})$ to increase its coordination number by forming oxygen and/or halogen bridges causes a frequency lowering of the stretching modes in the condensed phases [3].

Infrared and Raman spectra of gaseous $\mathrm{SOF}_{2}$ were reported by Pace and Samuelson [4], whereas the infrared spectrum of gaseous $\mathrm{SOCl}_{2}$ was measured by Hopf and Paetzold [5]. Only the Raman spectrum of liquid $\mathrm{SOBr}_{2}$ is known [6].

The selenyl halides have melting and boiling points considerably higher than those of the thionyl halides [7]. Therefore, relatively high temperatures are necessary to record the spectra of the gaseous sub- stances. In that way were obtained for $\mathrm{SeOF}_{2}$ the infrared spectrum (at $100{ }^{\circ} \mathrm{C}$, [5]) and Raman spectrum (at $120{ }^{\circ} \mathrm{C},[8]$ ), and for $\mathrm{SeOCl}_{2}$ the infrared spectrum (unknown temperature, [5]). No data were found for gaseous $\mathrm{SeOBr}_{2}$ and therefore the frequencies obtained from a solution of the substance in acetonitrile [3] were taken for the calculations.

\section{Calculations}

Optimized structures and vibrational frequencies for $\mathrm{SOX}_{2}$ and $\mathrm{SeOX}_{2}$ were obtained at the Hartree-Fock level using the $6-31 \mathrm{G}^{*}$ basis set, or with density functional theory (DFT) methods by means of the B3LYP $[9,10]$ and B3PW91 $[9,11]$ functionals and using the 6-31G and 6-311G basis sets alone or augmented with diffuse and/or polarized functions. The calculations were made in all cases with the GAUSSIAN 03 set of programs [12]. The results of these calculations are available from the authors. These exploratory calculations showed that the B3PW91/6-31G* combination, which was selected before for the studies made on the $\mathrm{SO}_{2} \mathrm{X}_{2}$ [1] and $\mathrm{SO}_{2} \mathrm{XF}$ [2] molecules, allowed a relatively good reproduction of the experimental frequencies of the $\mathrm{SOX}_{2}$ molecules. Such calculation level was therefore adopted for the thionyl and also for the selenyl molecules, in order to have comparable results. 
Table 1. Calculated ${ }^{\mathrm{a}}$ and experimental geometrical parameters for the series $\mathrm{SOX}_{2}$ and $\mathrm{SeOX}_{2}(\mathrm{X}=\mathrm{F}, \mathrm{Cl}, \mathrm{Br})$.

\begin{tabular}{|c|c|c|c|c|c|c|c|c|c|c|c|}
\hline & \multicolumn{2}{|c|}{$\mathrm{SOF}_{2}$} & \multicolumn{2}{|c|}{$\mathrm{SOCl}_{2}$} & \multicolumn{2}{|c|}{$\mathrm{SOBr}_{2}$} & \multicolumn{2}{|c|}{$\mathrm{SeOF}_{2}$} & \multicolumn{2}{|c|}{$\mathrm{SeOCl}_{2}$} & \multirow{2}{*}{$\frac{\mathrm{SeOBr}_{2}}{\text { calcd. }}$} \\
\hline & calcd. & exp. [20] & calcd. & exp. [21] & calcd. & exp. [22] & calcd. & exp. [23] & calcd. & exp. [24] & \\
\hline \multicolumn{12}{|l|}{ Bonds (Å) } \\
\hline $\mathrm{S}(\mathrm{Se})=\mathrm{O}$ & 1.443 & $1.420(3)$ & 1.458 & $1.443(6)$ & 1.464 & $1.45^{\mathrm{b}}$ & 1.596 & $1.576(3)$ & 1.610 & $1.612(5)$ & 1.617 \\
\hline$S(\mathrm{Se})-\mathrm{X}$ & 1.621 & $1.583(3)$ & 2.122 & $2.076(6)$ & 2.277 & 2.27 (2) & 1.746 & $1.7295(45)$ & 2.228 & $2.204(5)$ & 2.376 \\
\hline \multicolumn{12}{|l|}{ Angles $\left({ }^{\circ}\right)$} \\
\hline $\mathrm{X}-\mathrm{S}(\mathrm{Se})=\mathrm{O}$ & 107.0 & $106.2(2)$ & 108.0 & $106.3(6)$ & 108.8 & $108(3)$ & 105.04 & $104.82(1)$ & 105.34 & $105.8(7)$ & 106.03 \\
\hline $\mathrm{X}-\mathrm{S}(\mathrm{Se})-\mathrm{X}$ & 92.6 & $92.2(3)$ & 98.8 & $96.1(7)$ & 98.3 & $96(2)$ & 92.30 & $92.22(10)$ & 97.81 & $96.8(7)$ & 98.17 \\
\hline
\end{tabular}

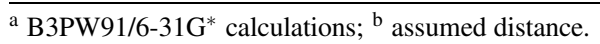
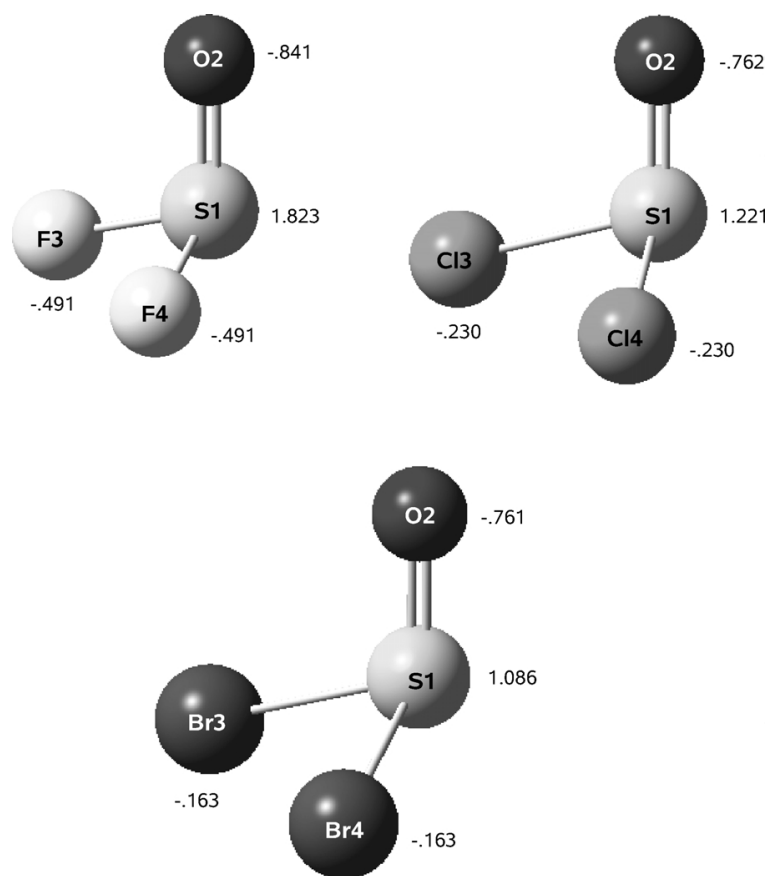

Fig. 1. The molecular structures and NBO atomic charges of the $\mathrm{SOX}_{2}$ species.

The harmonic force field in Cartesian coordinates given by the theoretical calculation was transformed to natural (local symmetry) coordinates [13] through the corresponding B matrix [14], calculated with a standard program. The resulting force field was subsequently scaled using the scheme of Pulay et al. [15], in which the diagonal force constants are multiplied by scale factors $f_{i} . f_{j}, \ldots$ and the corresponding interaction constants are multiplied by $\left(f_{i}, f_{j}\right)^{1 / 2}$, adjusting the scale factors by a least squares procedure to reproduce as well as possible the experimental frequencies. The potential energy distribution (PED), which gives the participation of each defined coordinate to each normal mode of vibration, was calculated with the resulting SQM (Scaled Quantum Mechanics) force field.
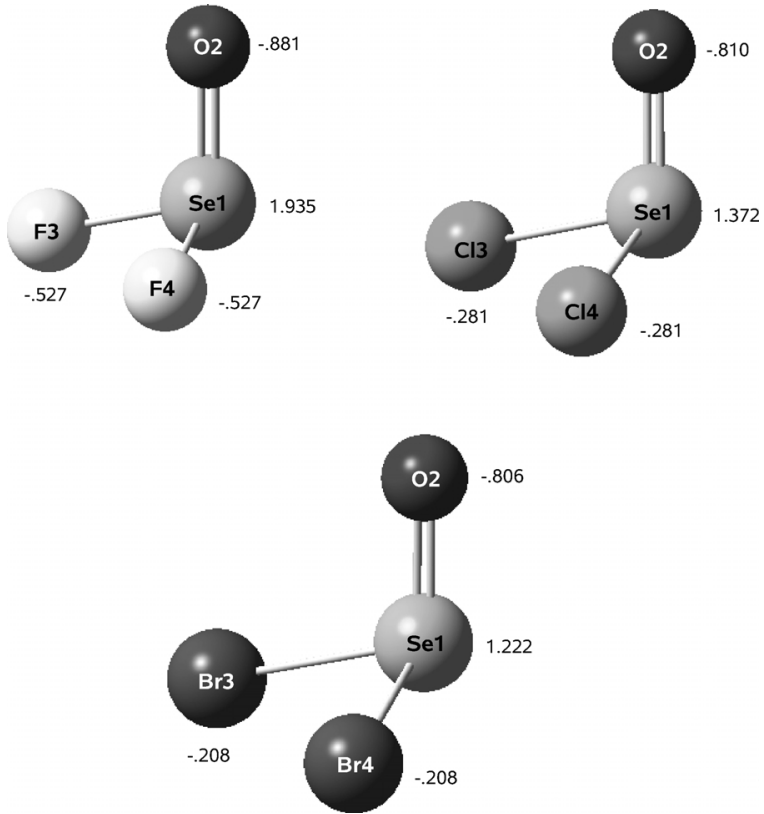

Fig. 2. The molecular structures and NBO atomic charges of the $\mathrm{SeOX}_{2}$ species.

The force field transformation, scaling and PED calculation were performed with the program FCARTP [16]. The atomic displacements given by the GAUSSIAN 03 programs for each vibrational mode, represented graphically by means of the program MOLDRAW [17], served to understand qualitatively the nature of the molecular vibrations.

Atomic charges and Wiberg bond indices [18] of the studied molecules were calculated by means of the Natural Bond Orbitals (NBO) approach [19], as implemented in the GAUSSIAN 03 package, using also the B3PW91/6-31G* combination.

\section{Structural Results}

The geometry optimization procedures predicted in all cases the expected pyramidal structures of $C_{S}$ symmetry shown in Figs. 1 and 2. The obtained geo- 
Table 2. Natural internal coordinates for the series $\mathrm{S}(\mathrm{Se}) \mathrm{OX}_{2}$.

Definition (according to Fig. 1) Description $^{\mathrm{a}}$

\begin{tabular}{ll}
\hline$A^{\prime}$ & \\
$\mathrm{S}_{1}=d(1-2)$ & $v \mathrm{~S}(\mathrm{Se})=\mathrm{O}$ \\
$\mathrm{S}_{2}=r(1-3)+r(1-4)$ & $v \mathrm{SX}_{2}$ symm. \\
$\mathrm{S}_{3}=\alpha(3-1-2)+\alpha(4-1-2)$ & wag. $\mathrm{SX}_{2}$ \\
$\mathrm{~S}_{4}=\beta(3-1-4)$ & $\delta \mathrm{SX}_{2}$ \\
$A^{\prime \prime}$ & \\
$\mathrm{S}_{5}=r(1-3)-r(1-4)$ & $v \mathrm{SX}_{2}$ antisymm. \\
$\mathrm{S}_{6}=\alpha(3-1-2)-\alpha(4-1-2)$ & $\rho \mathrm{SX}_{2}$ \\
\hline
\end{tabular}

${ }^{\mathrm{a}} v$, stretching; $\delta$, deformation; $\rho$, rocking
Table 3. Scaling factors for the force field of the series $\mathrm{S}(\mathrm{Se}) \mathrm{OX}_{2}$.

\begin{tabular}{|c|c|c|c|c|c|c|}
\hline Coordinates $^{\mathrm{a}}$ & $\mathrm{SOF}_{2}$ & $\mathrm{SOCl}_{2}$ & $\mathrm{SOBr}_{2}$ & $\mathrm{SeOF}_{2}$ & $\mathrm{SeOCl}_{2}$ & $\mathrm{SeOBr}_{2}$ \\
\hline $\mathrm{S}=\mathrm{O}$ & 0.997 & 1.000 & 0.820 & 0.930 & 0.931 & 0.908 \\
\hline$v \mathrm{SX}_{2}$ & 0.910 & 1.096 & 0.866 & 0.880 & 0.935 & 0.814 \\
\hline $\begin{array}{l}\text { wag. } \mathrm{SX}_{2}, \rho \mathrm{SX} \\
\quad \delta \mathrm{SX}_{2}\end{array}$ & , 1.191 & 1.180 & 1.040 & 1.126 & 1.193 & 1.038 \\
\hline
\end{tabular}

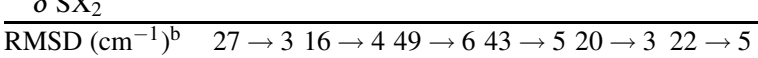

${ }^{\mathrm{a}} v$, stretching; $\delta$, deformation; $\rho$, rocking; ${ }^{\mathrm{b}}$ root Mean Square Deviation of calculated frequencies compared with experimental frequencies, before and after scaling of the force constants.

Table 4. Experimental and calculated frequencies and potential energy distributions for the $\mathrm{SOX}_{2}$ molecules. $_{\text {. }}$.

\begin{tabular}{|c|c|c|c|c|c|c|c|c|c|}
\hline \multirow[b]{2}{*}{ Mode } & \multicolumn{3}{|c|}{$\mathrm{SOF}_{2}$} & \multicolumn{3}{|c|}{$\mathrm{SOCl}_{2}$} & \multicolumn{3}{|c|}{$\mathrm{SOBr}_{2}$} \\
\hline & exp. [4] & calcd. SQM ${ }^{\mathrm{a}}$ & $\mathrm{PED}^{\mathrm{b}}$ & exp. [5] & calcd. SQM ${ }^{\mathrm{a}}$ & $\mathrm{PED}^{\mathrm{b}}$ & exp. [6] & calcd. SQM ${ }^{\mathrm{a}}$ & $\mathrm{PED}^{\mathrm{b}}$ \\
\hline \multicolumn{10}{|c|}{1 L 1} \\
\hline$v_{1}$ & 1330.4 & 1330 & $99 \mathrm{~S}_{1}$ & 1261 & 1261 & $100 S_{1}$ & 1121 & 1121 & $100 S_{1}$ \\
\hline$v_{2}$ & 808.2 & 805 & $81 \mathrm{~S}_{2}$ & 500 & 506 & $56 \mathrm{~S}_{2}+29 \mathrm{~S}_{3}$ & 405 & 411 & $40 \mathrm{~S}_{2}+41 \mathrm{~S}_{3}$ \\
\hline$v_{3}$ & 530.4 & 536 & $67 S_{3}+17 S_{2}$ & 354 & 353 & $62 S_{3}+41 S_{2}$ & 267 & 263 & $55 \mathrm{~S}_{3}+54 \mathrm{~S}_{2}$ \\
\hline$v_{4}$ & 377.8 & 374 & $99 \mathrm{~S}_{4}+32 \mathrm{~S}_{3}$ & 194 & 191 & $103 \mathrm{~S}_{4}+21 \mathrm{~S}_{3}$ & 120 & 114 & $99 \mathrm{~S}_{4}+16 \mathrm{~S}_{3}$ \\
\hline \multicolumn{10}{|l|}{$A^{\prime \prime}$} \\
\hline$v_{5}$ & 747.0 & 749 & $93 \mathrm{~S}_{5}$ & 464 & 458 & $64 S_{5}+41 S_{6}$ & 379 & 386 & $52 \mathrm{~S}_{5}+50 \mathrm{~S}_{6}$ \\
\hline$v_{6}$ & 392.5 & 391 & $92 \mathrm{~S}_{6}$ & 283 & 287 & $59 S_{6}+37 S_{5}$ & 223 & 214 & $50 \mathrm{~S}_{6}+48 \mathrm{~S}_{5}$ \\
\hline \multicolumn{2}{|c|}{$\overline{\operatorname{RMSD}\left(\mathrm{cm}^{-1}\right)}$} & 3 & & & 4 & & & 6 & \\
\hline
\end{tabular}

${ }^{\mathrm{a}}$ from Scaled Quantum Mechanics force field (see text); ${ }^{\mathrm{b}}$ contributions $\geq 10 \%$.

Table 5. Experimental and calculated frequencies and potential energy distributions for the $\mathrm{SeOX}_{2}$ molecules.

\begin{tabular}{|c|c|c|c|c|c|c|c|c|c|}
\hline \multirow[b]{2}{*}{ Mode } & \multicolumn{3}{|c|}{$\mathrm{SeOF}_{2}$} & \multicolumn{3}{|c|}{$\mathrm{SeOCl}_{2}$} & \multicolumn{3}{|c|}{$\mathrm{SeOBr}_{2}$} \\
\hline & exp. $[5,8]$ & calcd. SQM ${ }^{\mathrm{a}}$ & $\mathrm{PED}^{\mathrm{b}}$ & exp. [5] & calcd. SQM ${ }^{\mathrm{a}}$ & $\mathrm{PED}^{\mathrm{b}}$ & exp. [3] & calcd. SQM ${ }^{\mathrm{a}}$ & $\mathrm{PED}^{\mathrm{b}}$ \\
\hline \multicolumn{10}{|l|}{$\overline{A^{\prime}}$} \\
\hline$v_{1}$ & 1037 & 1037 & $100 \mathrm{~S}_{1}$ & 991 & 991 & $100 \mathrm{~S}_{1}$ & 961 & 961 & $100 S_{1}$ \\
\hline$v_{2}$ & $667 *$ & 662 & $96 \mathrm{~S}_{2}$ & 390 & 389 & $85 \mathrm{~S}_{2}$ & 284 & 286 & $52 \mathrm{~S}_{2}+34 \mathrm{~S}_{3}$ \\
\hline$v_{3}$ & 382 & 379 & $83 \mathrm{~S}_{3}$ & 278 & 283 & $84 \mathrm{~S}_{3}+14 \mathrm{~S}_{2}$ & 223 & 214 & $62 S_{3}+47 S_{2}$ \\
\hline$v_{4}$ & 270 & 279 & $102 \mathrm{~S}_{4}$ & 167 & 166 & $104 S_{4}+14 S_{3}$ & 96 & 97 & $104 S_{4}+13 S_{3}$ \\
\hline \multicolumn{10}{|l|}{$A^{\prime \prime}$} \\
\hline$v_{5}$ & $637^{*}$ & 642 & $97 \mathrm{~S}_{5}$ & 362 & 363 & $82 S_{5}+18 S_{6}$ & 270 & 278 & $51 S_{5}+49 S_{6}$ \\
\hline$v_{6}$ & 308 & 304 & $99 \mathrm{~S}_{6}$ & 264 & 260 & $82 \mathrm{~S}_{6}+17 \mathrm{~S}_{5}$ & 199 & 196 & $51 \mathrm{~S}_{6}+49 \mathrm{~S}_{5}$ \\
\hline \multicolumn{2}{|c|}{$\overline{\operatorname{RMSD}\left(\mathrm{cm}^{-1}\right)}$} & 5 & & & 3 & & & 5 & \\
\hline
\end{tabular}

* bands from Raman spectrum; ${ }^{\text {a }}$ from Scaled Quantum Mechanics force field (see text); ${ }^{\mathrm{b}}$ contributions $\geq 10 \%$.

Table 6. Internal force constants for the series $\mathrm{SOX}_{2}$.

\begin{tabular}{|c|c|c|c|c|c|c|c|c|}
\hline \multirow[b]{2}{*}{ Force constant ${ }^{\mathrm{a}}$} & \multicolumn{3}{|c|}{$\mathrm{SOF}_{2}$} & \multicolumn{3}{|c|}{$\overline{\mathrm{SOCl}_{2}}$} & \multicolumn{2}{|c|}{$\mathrm{SOBr}_{2}$} \\
\hline & this work & SH [25] & HP [5] & this work & SH [25] & HP [5] & this work & SH [25] \\
\hline \multicolumn{9}{|l|}{ Bond stretchings } \\
\hline$f(\mathrm{~S}=\mathrm{O})$ & 11.032 & 10.853 & 10.85 & 10.016 & 9.711 & 9.89 & 7.917 & 7.807 \\
\hline$f(\mathrm{~S}-\mathrm{X})$ & 3.966 & 3.972 & 4.16 & 1.839 & 1.787 & 2.23 & 1.446 & 1.525 \\
\hline$f(\mathrm{~S}=\mathrm{O} / \mathrm{S}-\mathrm{X})$ & 0.230 & - & - & 0.228 & - & - & 0.161 & - \\
\hline$f(\mathrm{~S}-\mathrm{X} / \mathrm{S}-\mathrm{X})$ & 0.276 & - & 0.44 & 0.336 & - & 0.32 & 0.230 & - \\
\hline$f(\mathrm{~S}-\mathrm{X} / \mathrm{X}-\mathrm{S}-\mathrm{X})$ & 0.102 & - & - & 0.071 & - & - & 0.076 & - \\
\hline$f(\mathrm{~S}-\mathrm{X} / \mathrm{X}-\mathrm{S}=\mathrm{O})^{\mathrm{b}}$ & 0.008 & -0.369 & - & 0.026 & -0.143 & - & 0.002 & -0.121 \\
\hline \multicolumn{9}{|l|}{ Angular deformations } \\
\hline$f(\mathrm{X}-\mathrm{S}=\mathrm{O})$ & 1.767 & 1.781 & 1.70 & 1.463 & 1.374 & 1.20 & 1.138 & 1.051 \\
\hline$f(\mathrm{X}-\mathrm{S}-\mathrm{X})$ & 1.833 & 1.849 & 1.51 & 1.308 & 1.184 & 1.12 & 1.060 & 1.134 \\
\hline$f(\mathrm{X}-\mathrm{S}=\mathrm{O} / \mathrm{X}-\mathrm{S}=\mathrm{O})$ & 0.441 & 0.574 & 0.43 & 0.347 & 0.407 & 0.27 & 0.274 & 0.285 \\
\hline$f(\mathrm{X}-\mathrm{S}=\mathrm{O} / \mathrm{X}-\mathrm{S}-\mathrm{X})$ & 0.431 & - & - & 0.358 & - & - & 0.291 & - \\
\hline
\end{tabular}

${ }^{a}$ units are mdyn $\AA^{-1}$ for stretchings and stretch/stretch interactions and mdyn $\AA$ rad $^{-2}$ for angular deformations; ${ }^{\mathrm{b}}$ bond/adjacent angle interaction constant. 
Table 7. Internal force constants for the series $\mathrm{SeOX}_{2}$.

\begin{tabular}{|c|c|c|c|c|c|c|c|}
\hline \multirow[b]{2}{*}{ Force constant $^{\mathrm{a}}$} & \multicolumn{3}{|c|}{$\mathrm{SeOF}_{2}$} & \multicolumn{3}{|c|}{$\mathrm{SeOCl}_{2}$} & \multirow{2}{*}{$\frac{\mathrm{SeOBr}_{2}}{\text { this work }}$} \\
\hline & this work & SH [25] & $\mathrm{HP}[5]$ & this work & SH [25] & HP [5] & \\
\hline \multicolumn{8}{|l|}{$\overline{\text { Bond stretchings }}$} \\
\hline$f(\mathrm{Se}=\mathrm{O})$ & 8.404 & 7.875 & 8.37 & 7.714 & 7.035 & 7.67 & 7.262 \\
\hline$f(\mathrm{Se}-\mathrm{X})$ & 3.754 & 3.320 & 3.57 & 1.898 & 1.831 & 1.97 & 1.448 \\
\hline$f(\mathrm{Se}=\mathrm{O} / \mathrm{Se}-\mathrm{X})$ & 0.158 & - & - & 0.176 & - & - & 0.150 \\
\hline$f(\mathrm{Se}-\mathrm{X} / \mathrm{Se}-\mathrm{X})$ & 0.140 & - & 0.37 & 0.230 & - & 0.23 & 0.182 \\
\hline$f(\mathrm{Se}-\mathrm{X} / \mathrm{X}-\mathrm{Se}-\mathrm{X})$ & -0.016 & - & - & 0.038 & - & - & 0.044 \\
\hline$f(\mathrm{Se}-\mathrm{X} / \mathrm{X}-\mathrm{Se}=\mathrm{O})^{\mathrm{b}}$ & -0.093 & -0.941 & - & -0.025 & -0.479 & - & -0.025 \\
\hline \multicolumn{8}{|l|}{ Angular deformations } \\
\hline$f(\mathrm{X}-\mathrm{Se}=\mathrm{O})$ & 1.349 & 1.656 & 1.36 & 1.270 & 1.169 & 1.15 & 1.004 \\
\hline$f(\mathrm{X}-\mathrm{Se}-\mathrm{X})$ & 1.251 & 1.056 & 1.05 & 1.168 & 0.651 & 1.03 & 0.891 \\
\hline$f(\mathrm{X}-\mathrm{Se}=\mathrm{O} / \mathrm{X}-\mathrm{Se}=\mathrm{O})$ & 0.268 & 0.369 & 0.27 & 0.204 & 0.362 & 0.10 & 0.165 \\
\hline$\underline{f(\mathrm{X}-\mathrm{Se}=\mathrm{O} / \mathrm{X}-\mathrm{Se}-\mathrm{X})}$ & 0.269 & - & - & 0.240 & - & - & 0.210 \\
\hline
\end{tabular}

${ }^{\mathrm{a}}$ units are mdyn $\AA^{-1}$ for stretchings and stretch/stretch interactions and mdyn $\AA$ rad $^{-2}$ for angular deformations; ${ }^{\mathrm{b}}$ bond/adjacent angle interaction constant.

metrical parameters are collected in Table 1, together with the available experimental data. Such data have originated from electron diffraction experiments [20$22,24]$, with the exception of $\mathrm{SeOF}_{2}$, which was studied by means of microwave techniques [23]. No structural data were found for $\mathrm{SeOBr}_{2}$ in the literature.

It can be seen that the larger differences between experimental and calculated distances amount to $0.02 \AA$ for $\mathrm{S}(\mathrm{Se}) \mathrm{O}$ bonds and $0.046 \AA$ for $\mathrm{S}(\mathrm{Se})-\mathrm{X}$ bonds. Angles are reproduced within $1^{\circ}$, save for $\mathrm{SOCl}_{2}$ in which case the larger difference amounts to $2.7^{\circ}$.

\section{Vibrational Results}

The six normal modes of vibration of the studied $\mathrm{S}(\mathrm{Se}) \mathrm{OX}_{2}$ molecules can be classified as $4 \mathrm{~A}^{\prime}+2 \mathrm{~A}^{\prime \prime}$, within the point group $C_{s}$.

There is agreement between the different authors regarding the assignments of the bands observed for $\mathrm{SOX}_{2}$ and $\mathrm{SeOX}_{2}$. The atomic displacement vectors given by the present calculations agree also with these assignments.

The harmonic force fields in Cartesian coordinates generated by the GAUSSIAN suite of programs for the studied molecules were transformed to the set of coordinates defined in Table 2. The resulting force constants were subsequently scaled according to the methodology proposed by Pulay et al. [15], as mentioned in the calculations section, in order to reproduce as well as possible the experimental frequencies.

The calculated scaling factors corresponding to each force constant of the six molecules appear in Table 3, in which is also shown the decrease in the RMSD (Root Mean Square Deviation) when comparing the experi- mental frequencies with the calculated ones, before and after scaling.

The SQM force fields obtained in that way were used to calculate the potential energy distribution. These values, as well as the experimental and calculated frequencies, are given in Tables 4 and 5. The internal force constants appearing in Tables 6 and 7 were also calculated from the SQM force fields (the corresponding force constants matrices are available from the authors).

\section{Discussion of the Results}

The obtained internal force constants are compared in Tables 6 and 7 with the values reported by Suthers and Henshall [25] and by Hopf and Paetzold [5]. Several interaction constants were not given by these authors and therefore the comparison is incomplete. There is a fair agreement between the main force constants, but the interaction constants differ in many cases. The relative values and signs of some interaction constants are discussed in [25] on the basis of the repulsive forces existing between the highly electronegative halogen atoms and the lone electron pair located on the central $\mathrm{S}$ and $\mathrm{Se}$ atoms. In fact, an increase in the $\mathrm{X}-\mathrm{S}(\mathrm{Se})=\mathrm{O}$ angle will result in a decrease in the halide/lone-pair separation, creating a strain which can be relieved by stretching of the $S(S e)-X$ bond; the net decrease of the molecular potential energy should be reflected in a negative sign of the $f[\mathrm{~S}(\mathrm{Se})-\mathrm{X} / \mathrm{X}-$ $\mathrm{S}(\mathrm{Se})=\mathrm{O}$ ] interaction constant. Such prediction is confirmed only for the selenyl compounds in the present study (Table 7). Following the same reasoning, the simultaneous opening of both $\mathrm{X}-\mathrm{S}(\mathrm{Se})=\mathrm{O}$ angles should increase the potential energy, justifying the positive 
Table 8. Experimental frequencies and additional data for the $\mathrm{SOX}_{2}$ molecules.

\begin{tabular}{lrrr}
\hline Mode $^{\mathrm{a}}$ & $\mathrm{SOF}_{2}$ & $\mathrm{SOCl}_{2}$ & $\mathrm{SOBr}_{2}$ \\
\hline$v \mathrm{~S}=\mathrm{O}$ & 1330.4 & 1261 & 1121 \\
$v \mathrm{SX}_{2}$ symmetric & 808.2 & 500 & 405 \\
$v \mathrm{SX}_{2}$ antisymm. & 747.0 & 464 & 379 \\
wag. $\mathrm{SX}_{2}$ & 530.4 & 354 & 267 \\
rock. $\mathrm{SX}_{2}$ & 392.5 & 283 & 223 \\
$\delta \mathrm{SX}$ & 377.8 & 194 & 120 \\
$d \mathrm{~S}=\mathrm{O}(\AA$, calc. $)$ & 1.443 & 1.458 & 1.464 \\
$f \mathrm{~S}=\mathrm{O}\left(\right.$ mdyn $\left.\AA^{-1}\right)$ & 11.032 & 10.016 & 7.917 \\
$W I \mathrm{~S}=\mathrm{O}^{\mathrm{b}}$ & 1.551 & 1.475 & 1.439 \\
$d \mathrm{~S}-\mathrm{X}(\AA$, calc. & 1.621 & 2.122 & 2.277 \\
$f \mathrm{~S}-\mathrm{X}\left(\right.$ mdyn $\left.\AA^{-1}\right)$ & 3.966 & 1.839 & 1.446 \\
$W I \mathrm{~S}-\mathrm{X}^{\mathrm{b}}$ & 0.687 & 0.807 & 0.820 \\
\hline
\end{tabular}

${ }^{\mathrm{a}} v$, stretching; $\delta$, deformation; ${ }^{\mathrm{b}}$ Wiberg index [18] calculated with the NBO method [19].

sign of $f[\mathrm{X}-\mathrm{S}(\mathrm{Se})=\mathrm{O} / \mathrm{X}-\mathrm{S}(\mathrm{Se})=\mathrm{O}]$. The same argument is used to account for the occurrence of higher frequencies for the symmetric $\mathrm{S}(\mathrm{Se}) \mathrm{X}_{2}$ stretching frequencies in comparison with the antisymmetric ones, reversing the trend which is usual in other molecules, such as the sulfuryl halides $[1,2]$.

The experimental frequencies for the $\mathrm{SOX}_{2}$ and $\mathrm{SeOX}_{2}$ molecules are collected in Tables 8 and 9 together with some internal force constants, interatomic distances and Wiberg indices. The positive charge on the central atoms decreases with the decreasing electronegativity of the halogen along the series, as shown in Figs. 1 and 2. This is accompanied by a smaller electron back-donation from the oxygen atom reinforcing the $\mathrm{S}=\mathrm{O}$ or $\mathrm{Se}=\mathrm{O}$ bond, as mentioned also by Suthers and Henshall [25]. The consequence is a decrease of the $\mathrm{S}(\mathrm{Se})=\mathrm{O}$ bond order (as measured by the Wiberg index) and in the corresponding force con-
Table 9. Experimental frequencies and additional data for the $\mathrm{SeOX}_{2}$ molecules.

\begin{tabular}{|c|c|c|c|}
\hline Mode $^{a}$ & $\mathrm{SeOF}_{2}$ & $\mathrm{SeOCl}_{2}$ & $\mathrm{SeOBr}_{2}$ \\
\hline$v \mathrm{Se}=\mathrm{O}$ & 1037 & 991 & 961 \\
\hline$v \mathrm{SeX}_{2}$ symmetric & 667 & 390 & 284 \\
\hline$v \mathrm{SeX}_{2}$ antisymm. & 637 & 362 & 270 \\
\hline wag. $\mathrm{SeX}_{2}$ & 382 & 278 & 223 \\
\hline rock. $\mathrm{SeX}_{2}$ & 308 & 264 & 199 \\
\hline$\delta \mathrm{SeX}_{2}$ & 270 & 167 & 96 \\
\hline$d \mathrm{Se}=\mathrm{O}(\AA$, calc $)$ & 1.596 & 1.610 & 1.617 \\
\hline$f \mathrm{Se}=\mathrm{O}\left(\operatorname{mdyn}^{\circ} \AA^{-1}\right)$ & 8.404 & 7.714 & 7.262 \\
\hline$W I \mathrm{Se}=\mathrm{O}^{\mathrm{b}}$ & 1.505 & 1.450 & 1.414 \\
\hline$d \mathrm{Se}-\mathrm{X}(\AA$, calc. $)$ & 1.746 & 2.228 & 2.376 \\
\hline$f \mathrm{Se}-\mathrm{X}\left(\mathrm{mdyn} \AA^{-1}\right)$ & 3.754 & 1.898 & 1.448 \\
\hline WI S-X & 0.646 & 0.800 & 0.826 \\
\hline
\end{tabular}

${ }^{\text {a }} v$, stretching; $\delta$, deformation; ${ }^{\text {b }}$ Wiberg index [18] calculated with the NBO method [19].

stants, whereas the $\mathrm{S}(\mathrm{Se})=\mathrm{O}$ bond length increases (Tables 8 and 9).

The $\mathrm{S}(\mathrm{Se})-\mathrm{X}$ distances show the expected increase along the series on account of the increasing covalent radius of the halogen atoms. A larger participation of the halogen electrons in the $\mathrm{S}(\mathrm{Se})-\mathrm{X}$ bonds is expected with decreasing halogen electronegativity along the series, explaining the increasing Wiberg indices. The corresponding force constants, however, show a decrease related to the increasing $\mathrm{S}(\mathrm{Se})-\mathrm{X}$ bond lengths.

\section{Acknowledgement}

Research grants from the following institutions from R. Argentina are gratefully acknowledged: CONICET (Consejo Nacional de Investigaciones Científicas y Técnicas), ANPCYT (Agencia Nacional de Promoción Científica y Tecnológica, BID 1728/OC-AR, PICT 11127), UNLP (Universidad Nacional de La Plata) and CIUNT (Consejo de Investigaciones de la Universidad Nacional de Tucumán).
[1] L.E. Fernández, M. G. Verón, E.L. Varetti, Spectrochim. Acta 2004, 60A, 405.

[2] L. E. Fernández, E. L. Varetti, Spectrochim. Acta 2005, $62 A, 221$.

[3] J. Milne, Spectrochim. Acta 1982, 38A, 569.

[4] E. L. Pace, H. V. Samuelson, J. Chem. Phys. 1965, 44, 3682.

[5] G. Hopf, R. Paetzold, Z. Phys. Chemie 1972, 251, 273.

[6] H. Stammreich, R. Forneris, Y. Tavares, J. Chem. Phys. 1956, 25, 1277.

[7] Handbook of Chemistry and Physics, $72^{\text {nd }}$ Ed. (Ed.: D. R. Lide), CRC Press, Boston, 1991, p. 4-94 and 4106.

[8] L.E. Alexander, I. R. Beattie, J. Chem. Soc., Dalton Trans. 1972, 1745.
[9] A. D. Becke, J. Chem. Phys. 1993, 98, 5648.

[10] C. Lee, W. Yang, R. G. Parr, Phys. Rev. 1988, B37, 785.

[11] J. P. Perdew, K. Burke, Y. Wang, Phys. Rev. 1996, B54, 16533.

[12] M. J. Frisch, G.W. Trucks, H. B. Schlegel, G.E. Scuseria, M. A. Robb, J. R. Cheeseman, J. A. Montgomery, Jr., T. Vreven, K. N. Kudin, J.C. Burant, J. M. Millam, S. S. Iyengar, J. Tomasi, V. Barone, B. Mennucci, M. Cossi, G. Scalmani, N. Rega, G. A. Petersson, H. Nakatsuji, M. Hada, M. Ehara, K. Toyota, R. Fukuda, J. Hasegawa, M. Ishida, T. Nakajima, Y. Honda, O. Kitao, H. Nakai, M. Klene, X. Li, J.E. Knox, H.P. Hratchian, J. B. Cross, C. Adamo, J. Jaramillo, R. Gomperts, R. E. Stratmann, O. Yazyev, A.J. Austin, R. Cammi, 
C. Pomelli, J.W. Ochterski, P. Y. Ayala, K. Morokuma, G. A. Voth, P. Salvador, J. J. Dannenberg, V. G. Zakrzewski, S. Dapprich, A.D. Daniels, M. C. Strain, O. Farkas, D. K. Malick, A. D. Rabuck, K. Raghavachari, J. B. Foresman, J. V. Ortiz, Q. Cui, A. G. Baboul, S. Clifford, J. Cioslowski, B. B. Stefanov, G. Liu, A. Liashenko, P. Piskorz, I. Komaromi, R. L. Martin, D. J. Fox, T. Keith, M. A. Al-Laham, C. Y. Peng, A. Nanayakkara, M. Challacombe, P. M. W. Gill, B. Johnson, W. Chen, M. W. Wong, C. Gonzalez, J. A. Pople, Gaussian 03, Gaussian, Inc., Pittsburgh, PA (USA) 2003.

[13] G. Fogarasi, X. Zhou, P.W. Taylor, P. Pulay, J. Am. Chem. Soc. 1992, 114, 8191.

[14] E. B. Wilson, J. C. Decius, P. C. Cross, Molecular Vibrations, McGraw-Hill, New York, 1955.

[15] P. Pulay, G. Fogarasi, G. Pongor, J.E. Boggs, A.Vargha, J. Am. Chem. Soc. 1983, 105, 7037.
[16] W. B. Collier, Program FCARTP (QCPE \#631), Department of Chemistry, Oral Roberts University, Tulsa, OK (USA) 1992.

[17] P. Ugliengo, D. Viterbo, G. Chiari, Z. Kristallogr. 1993, 207, 9.

[18] K. B. Wiberg, Tetrahedron 1968, 24, 1083.

[19] A. E. Reed, L. A. Curtiss, F. Weinhold, Chem. Rev. 1988, $88,899$.

[20] I. Hargittai, F. C. Mijlhoff, J. Mol. Struct. 1973, 16, 69.

[21] I. Hargittai, Acta Chim. Hung. 1969, 60, 231.

[22] D. P. Stevenson, R. A. Cooley, J. Am. Chem. Soc. 1940, 62, 2477.

[23] L. C. Bowater, R. D. Brown, F. R. Burden, J. Mol. Spectrosc. 1968, 28, 461.

[24] D. Gregory, I. Hargittai, M. Kolonits, J. Mol. Struct. 1976, 31, 261.

[25] R. A. Suthers, T. Henshall, Z. Anorg. Allg. Chem. 1972 , 388, 269. 